\title{
The Incidence and Characteristics of Chronic Postoperative Groin Pain after Inguinal Hernia Repair with Different Types of Prolene Mesh
}

\author{
D Grebić ${ }^{1}$, AM Tomašić ${ }^{2}$, L Valenčić 2 , N Trbojević ${ }^{2}$, H Grbas ${ }^{1}$
}

\begin{abstract}
Objective: The objective of this study is to show the incidence and characteristics of chronic groin pain after inguinal hernia repair using different types of prolene mesh.

Methods: The study was undertaken at the Department of Surgery, Clinical Hospital Centre Rijeka, and included 180 patients who had undergone inguinal hernia repair six to eight months prior to examination. Inguinal canal plasty had been done in 90 patients using a small-pored prolene mesh and in 90 patients using a large-pored prolene mesh. Every patient had undergone the Lichtenstein technique and preservation of inguinal nerves. Patients who felt pain were invited to complete a pain quality assessment scale (PQAS) with 20 items scored on a 0 to 10 numeric rating scale.

Results: In the group of patients who had undergone inguinal canal plasty using a small-pored prolene mesh, 16 (18\%) of the 90 patients had chronic postoperative groin pain. In the group of patients (90 patients) that had undergone inguinal canal plasty using a large-pored prolene mesh, none expressed chronic postoperative groin pain. The Pain Quality Assessment Scale is divided into three sub-scales. The first sub-scale evaluates paroxysmal pain. The mean value on this sub-scale was 2.56 , which pertains to mild pain. The second sub-scale examines superficial pain, which had a mean value of 2.08 , and the third subscale evaluates deep pain, which had a mean value of 1.89. All values pertained to mild pain.

Conclusion: Using small-pored mesh for inguinal hernia repair increases the incidence of postoperative groin pain.
\end{abstract}

Keywords: Inguinal hernia, large-pored prolene mesh, postoperative chronic groin pain, small-pored prolene mesh

\section{Incidencia y Características del Dolor Crónico Postoperatorio de la Ingle tras la Reparación de la Hernia Inguinal con Diferentes tipos de Malla Prolene}

\author{
D Grebić ${ }^{1}$, AM Tomašić ${ }^{2}$, L Valenčić 2 , N Trbojević ${ }^{2}, H_{\text {Grbas }}{ }^{1}$
}

\begin{abstract}
RESUMEN
Objetivo: Este estudio muestra la incidencia y las características del dolor crónico en la ingle después de la reparación de la hernia inguinal utilizando diferentes tipos del prolene.

Métodos: El estudio se llevó a cabo en el departamento de cirugía, hospital Rijeka, donde se examinaron 180 pacientes sometidos a la reparación de hernia inguinal 6-8 meses antes de la prueba. Plastia canal inguinal se hizo en 90 pacientes utilizando una malla de prolene de poro pequeño y en 90 con poro grande. Cada paciente fue sometido a la técnica de Lichtenstein y la preservación de nervios inguinales.

Los pacientes con dolor fueron invitados a completar una evaluación del dolor de calidad con 20 elementos calificados en una escala de 0 a 10.

Resultados: En el grupo de pacientes que fueron sometidos a plastia canal inguinal usando un prolene de pequeños poros, 16 (18\%) de los 90 pacientes tenían dolor inguinal crónico postoperatorio. En el otro grupo de pacientes que fueron sometidos, utilizando una malla de prolene de poros grandes, ninguno sentía dolor inguinal crónico postoperatorio.

La escala de calidad de evaluación del dolor se divide en tres sub-escalas. La primera evalúa el dolor paroxístico. La media fue de 2.56. La segunda examina el dolor superficial, cuya media es de 2.08, y la
\end{abstract}

From: ${ }^{1}$ Department of Surgery, School of Medicine, Clinical Hospital Centre Rijeka, University of Rijeka, Krešimirova 42, Rijeka, Croatia and ${ }^{2}$ Medical Faculty of Rijeka, School of Medicine, Braće Branchetta 20, Rijeka, Croatia.
Correspondence: Dr D Grebić, Department of Surgery, Clinical Hospital Centre, Rijeka, Krešimirova 42, 51000 Rijeka, Croatia. Email: damir.grebic@ medri.uniri.hr 
tercera evalúa el dolor profundo, con una media de 1,89. Todos estos resultados nos indican un dolor leve. Conclusión: El uso de malla de poros pequeños aumenta la incidencia de dolor en la ingle postoperatoria.

Palabras clave: Hernia inguinal, malla de poros grandes, dolor crónico postoperatorio, malla de poros pequeños

West Indian Med J 2017; 66 (1): 47

\section{INTRODUCTION}

An inguinal hernia is the protrusion of the contents of the abdominal cavity through the inguinal canal. Approximately 20 million people suffer from this condition, and is a significant public health problem. About $75 \%$ of all hernias occur in the groin, with a notably higher incidence in men (1).

Chronic pain that occurs after inguinal hernia repair is the most common complication of surgical procedures, present among $5-63 \%$ of treated patients $(2,3)$. Chronic inguinal pain is defined as persistent pain 3-6 months after inguinal hernia repair $(4,5)$. Neuropathic and somatic pain are the two most commonly exhibited types of chronic pain $(6,7)$. Chronic pain, also known as causalgia syndrome, affects three inguinal nerves: the ilioinguinal, the iliohypogastric, and the genital branch of the genitofemoral nerve, which presents many aberrations, making it difficult to identify (8). Causes of neuropathic chronic groin pain may include adhesion of a nerve to the mesh, suture entrapment, or perioperative iatrogenic nerve injury. This type of pain presents as a sharp, stabbing, or burning sensation triggered by moving or heavy lifting $(9,10)$. Somatic causes of pain include recurrent inguinal hernia, tension from the mesh, or placing a suture through the periost of the pubic tubercle, which manifests as tenderness and a shooting, cramping sensation (11). The mesh is prone to shrinkage, especially a small-pored mesh, which can also cause neuropathic and somatic pain (12). Predictive risk factors for chronic postoperative pain include: preoperative pain, repeat surgery, psychological co-morbid conditions, surgical approach with an increased risk of nerve damage, radiation and chemotherapy (13). Differential diagnosis of chronic inguinal pain includes musculoskeletal groin disorders like bursitis, tendinitis, osteoarthritis, avascular necrosis of the femoral head and avulsion fractures. Also, there are many nonorthopaedic conditions which can manifest as inguinal pain, such as urinary tract infections, lymphadenitis, hydrocaele, varicocaele, scrotal masses, kidney stones and polycystic ovaries (14). The objective of this study is to show the incidence and characteristics of chronic groin pain after inguinal hernia repair using different types of prolene mesh.

\section{SUBJECTS AND METHODS}

The proposed study was undertaken at the Department of Surgery, Division for General Surgery, Clinical Hospital Centre Rijeka, where 180 patients were considered who had undergone inguinal hernia repair 6 -8 months prior to examination. Informed consent was obtained from each patient. The study was retrospective and included only male patients, mean age
58 years (21, the youngest, 79 , the oldest). As we analysed the incidence and characteristics of chronic postoperative groin pain (only pain that could be a consequence of surgical hernia repair), in order to obtain the objective results, the study excluded patients with incarcerated hernias, chronic infections, general or systemic diseases as carcinomas, patients who lost the motor and sensory function due to the central or peripheral systemic disorder as all of these conditions may be potential cause for groin pain. Among 180 patients that were retrospectively chosen, inguinal canal plasty had been done in 90 patients using a small-pored prolene mesh and in 90 patients using a large-pored prolene mesh. Large-pored prolene mesh was determined by 1-2 $\mathrm{mm}$ pore size (Covidien) and smallpored prolene mesh was determined by $3 \mu \mathrm{m}$ pore size (Brown).

Every patient had been undergone Lichtenstein technique and there was preservation of inguinal nerves. The original Lichtenstein technique was used, which is performed as follows: after hernia reparation, a polypropylene mesh is placed on the posterior wall of the inguinal canal and fixed with sutures to the pubic tubercle, and then to the free edge of the inguinal ligament. The continuous suture extends up to the anterior superior iliac spine.

After evaluation of all 180 patients, only those who felt the pain were invited to complete a questionnaire in order to analyse the characteristics and properties of their pain. For this purpose, the pain quality assessment scale PQAS questionnaire was used. The PQAS questionnaire is a scale with 20 items that are scored on a 0 to 10 numeric rating scale. The patients were invited to complete the 20 subjective questions about the characteristics of their pain. A score of 0 indicates no pain, $1-$ 3 mild pain, 4-6 moderate pain and 7-10 severe pain.

The statistical significance of the incidence of postoperative groin pain between the group of the patients treated by small-pored prolene mesh and those treated by large-pored prolene mesh was determined using $\chi^{2}$ test. Statistical analyses were completed using the Statistical Package for the Social Sciences (SPSS). Probability ( $p$ ) values less than 0.001 were considered statistically significant.

\section{RESULTS}

Of the total number of patients, $16(8.89 \%)$ patients had pain in the operated area. In the group of patients who had undergone inguinal canal plasty using a small-pored prolene mesh $16(18 \%)$ of the 90 patients had chronic postoperative groin pain. In the group of patients ( 90 patients) that had undergone inguinal canal plasty using a large-pored prolene mesh, none 
exhibited chronic postoperative groin pain. $\chi^{2}$ test revealed a statistically significant difference in frequency of postoperative groin pain between patients treated by small-pored prolene mesh and those treated by large-pored prolene mesh $\left(\chi^{2}=\right.$ 17.6; $p<0.001$ ).

Only patients who felt pain were invited to complete PQAS questionnaire. The PQAS questionnaire was divided into three sub-scales and each sub-scale consisted of five items. The first sub-scale examines paroxysmal pain looking at sharpness, burning sensations, shooting pain, electrical sensations and radiation. The arithmetic mean for this cluster of items was 2.56 , which classifies it as mild pain of the paroxysmal type. Also, it is evident that the most expressed quality in this cluster was sharpness with a score of 3.44 (Fig. 1).

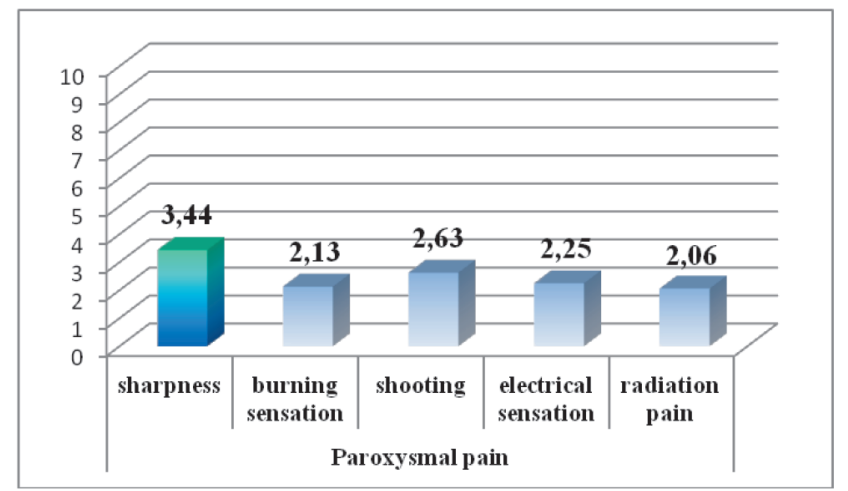

Fig. 1: Paroxysmal pain sub-scale. The $\mathrm{x}$-axis shows the evaluated items and the $y$-axis the numeric rating scale. Note that out of all of the items, sharpness is expressed the most.

The second sub-scale describes five characteristics of superficial pain: sensation of coldness, sensitivity, itchiness, numbness and tingling. The mean result we calculated is 2.08 and that represented mild superficial pain. Numbness was the most prominent quality of the superficial pain items (Fig. 2).

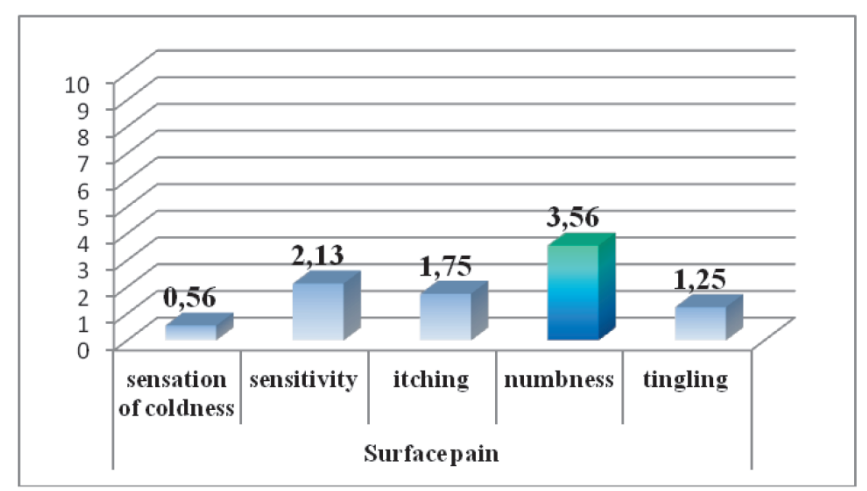

Fig. 2: Superficial pain sub-scale. The $\mathrm{x}$-axis shows the evaluated items and the $y$-axis the numeric rating scale. Patients found numbness as the leading quality of superficial pain.

The third sub-scale explores deep pain with dullness, cramping, throbbing, aching and feeling of pressure. The mean result was 1.89 which is mild, but is a lower result than for su- perficial pain. Dullness was the most prominent quality of the deep pain items (Fig. 3).

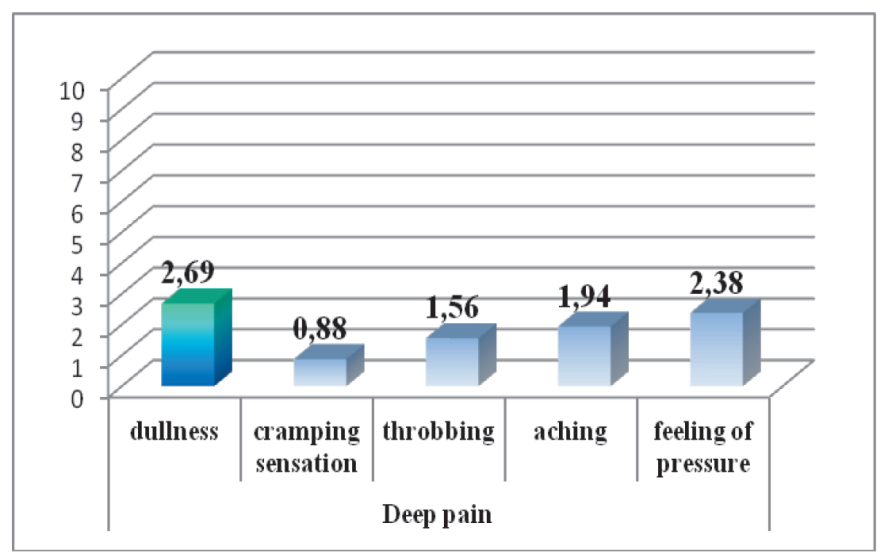

Fig. 3: Deep pain sub-scale. The $\mathrm{x}$-axis shows the evaluated items and the $\mathrm{y}$ axis the numeric rating scale. Observe that out of the all characteristics examined, dullness is expressed the most.

The statistical analyses showed that there were no statistical significance between occurrence and severity of deep and superficial pain (the coefficient of correlation was -0.276 , $p<0.005$ ).

Additionally, the arithmetic mean of pain intensity and unpleasantness was calculated. The results showed that the intensity of the pain, as well as unpleasantness, were mild (2.94 in both cases).

\section{DISCUSSION}

The incidence of chronic postoperative groin pain in this study was $8.89 \%$, which was statistically significance at $p<0.001$ and consistent with the results of other studies $(2,3)$. All 16 patients in this study who had chronic postoperative pain were operated on using small-pored meshes. The results are in correlation with other findings, as the application of such meshes increases the incidence of postoperative groin pain (12). Although these meshes are made of inert synthetic material, it has been proven that small-pored meshes cause a stronger reaction of the surrounding tissue and therefore irritate the nerves even more (15-18) than large-pored mesh as can be seen in our study. This could be explained by the fact that small pores, due to the stronger reaction of the surrounding tissue are tighter and disrupt ingrown structures, especially nerves $(11,12)$.

The Lichtenstein method is characterised by suturing the mesh, and if a nerve becomes captured in a suture, it can cause neuropathic pain. Primary injury to the nerves can also be caused by stretching, partial cutting, or injury from electrocautery. Non-neuropathic pain is not primarily related to nerve injury, but develops secondary, as a result of excessive scarring of tissue around the mesh or an inappropriate inflammatory response (14). It is important, during the suturing of the mesh, that the surgeon does not set the suture too deep in the periost of the pubic tubercle. The inflammatory response that 
can develop as osteitis can lead to aching and throbbing in the pubic region which is provoked by movement (15). It is evident that prophylactic neurectomy is the best prevention of postoperative pain, as is shown in other studies (15). Therefore, to obtain objective results in this study all inguinal nerves were identified and preserved in every patient.

Assessment of pain is very difficult and subjective. In this study, it was decided to use the PQAS questionnaire because it was considered to be the most extensive and reliable, and it was used for the evaluation of many types of chronic pain $(19,20)$. As can be seen in the results, the most frequent chronic pain that patients felt was paroxysmal. This can be explained by the role of nerve damage in the aetiology of the pain. Sharp, shooting pain occurs by the irritation of a damaged nerve by movement or position. The patients rated pain more as superficial pain rather than deep pain although it was not statistically significant. This is in accordance with the fact that superficial structures like nerves and muscles of the abdominal wall are at higher risk for damage during surgery. The fact that patients had not undergone neurectomy, might have contributed to the occurrence of superficial pain.

In conclusion, we emphasize that according to our results, inguinal plasty by using small-pored mesh increases the incidence of chronic postoperative groin pain due to the fact of stronger tissue reaction. According to the characteristics of the pain, most frequently, it was mild paroxysmal, discontinuous pain and none of the patients had pain to such degree that would impair their quality of life or restrict daily activities.

\section{REFERENCES}

1. Kulacoglu H. Current options in inguinal hernia repair in adult patients. Hippokratia 2011; 15: 223-31.

2. O'Dwyer PJ, Norrie J, Alani A, Walker A, Duffy F, Horgan P. Observation or operation for patients with an asymptomatic inguinal hernia: a randomised clinical trial. Ann Surg 2006; 244: 167-73.

3. Searle RD, Simpson KH. Chronic post-surgical pain. Cont Edu in Anaesth Crit Care and Pain 2010; 10: 12-4.

4. Campanelli G, Bertocchi V, Cavalli M, Bombini G, Biondi A, Tentorio T et al. Surgical treatment of chronic pain after inguinal hernia repair. Hernia $2013 ; 17: 347-53$.
5. Courtney CA, Duffy K, Serpell MG, O’Dwyer PJ. Outcome of patients with severe chronic pain following repair of groin hernia. Br J Surg 2002; 89: $1310-4$.

6. Poobalan AS, Bruce J, King PM, Chambers WA, Krukowski ZH, Smith WC. Chronic pain and quality of life following open inguinal hernia repair. Br J Surg 2001; 88: 1122-6.

7. Cunningham J, Temple WJ, Mitchell P, Nixon JA, Preshaw RM, Hagen NA. Cooperative hernia study, pain in the postrepair patient. Ann Surg 1996; 224: 598-602.

8. Kabir SF, Alam ABMK. Preoperative nerve preservation during open hernia repair. Bangladesh J Anat 2010; 8: 39-42.

9. Loos MJ, Scheltinga MR, Roumen RM. Tailored neurectomy for treatment of postherniorrhaphy inguinal neuralgia. Surgery 2010; 147: 275 81.

10. Loos MJ, Roumen RM, Scheltinga MR. Classifying post-herniorrhaphy pain syndromes following elective inguinal hernia repair. World J Surg 2007; 31: 1760-5.

11. de Lange DH, Wijsmuller AR, Aufenacker TJ, Rauwerda JA, Simons MP. Neuralgic pain, a significant complication after Lichtenstein hernia repair. Ned Tijdschr Geneeskd 2008; 152: 2205-9.

12. Shulman AG. Changes in technique of primary inguinal hernioplasty since 1984. The Lichtenstein hernia repairs, and how to do them right! Wagner design, ISBN 09653526-0-9, 1996; 49.

13. Macrae WA. Chronic pain after surgery. Br J Anaesth 2001; 87: 88-98.

14. Suarez JC, Ely EE, Mutnal AB, Figueroa NM, Klika AK, Patel PD et al. Comprehensive approach to the evaluation of groin pain. J Am Acad Orthop Surg 2013; 21: 558-70.

15. Zanghi G, Di Stefano G, Arena M, Di Dio D, Basile F. Iliohypogastric neurectomy in the prevention of postoperative pain following inguinal hernioplasty. G Chir 2012; 33: 172-4.

16. Demetrashvili Z, Qerqadze V, Kamkamidze G, Topchishvili G, Lagvilava L, Chartholani T et al. Comparison of Lichtenstein and laparoscopic transabdominal preperitoneal repair of recurrent inguinal hernias. Int Surg 2011; 96: 233-8.

17. Brown CN, Finch JG. Which mesh for hernia repair? Ann R Coll Surg Engl 2010; 92: 272-8.

18. Berrevoet F, Maes L, De Baerdemaeker L, Rogiers X, Troisi R, de Hemptinne B. Comparable results with 3-year follow-up for large-pore versus small-pore meshes in open incisional hernia repair. Surgery 2010; 148: $969-5$.

19. Berger D. Diagnostic and therapy of chronic pain following hernia operation. Chirurg 2014; 85: 117-20.

20. Victor TW, Jensen MP, Gammaitoni AR, Gould EM, White RE, Galer BS. The dimensions of pain quality: factor analysis of the Pain Quality Assessment Scale. Clin J Pain 2008; 24: 550-5. 